\title{
Enatiomerically pure hydroxycarboxylic acids: current approaches and future perspectives
}

\author{
Qun Ren • Katinka Ruth • Linda Thöny-Meyer • \\ Manfred Zinn
}

Received: 27 January 2010 /Revised: 24 February 2010 /Accepted: 24 February 2010 / Published online: 15 April 2010

(C) The Author(s) 2010. This article is published with open access at Springerlink.com

\begin{abstract}
The growing awareness of the importance of chirality in conjunction with biological activity has led to an increasing demand for efficient methods for the industrial synthesis of enantiomerically pure compounds. Polyhydroxyalkanotes (PHAs) are a family of polyesters consisting of over 140 chiral $R$-hydroxycarboxylic acids (R-HAs), representing a promising source for obtaining chiral chemicals from renewable carbon sources. Although some R-HAs have been produced for some time and certain knowledge of the production processes has been gained, large-scale production has not yet been possible. In this article, through analysis of the current advances in production of these acids, we present guidelines for future developments in biotechnological processes for R-HA production.
\end{abstract}

Keywords $R$-hydroxycarboxylic acids .

Polyhydroxyalkanotes (PHAs) .

Biotechnological processes $\cdot$ Chiral compounds

Electronic supplementary material The online version of this article (doi:10.1007/s00253-010-2530-6) contains supplementary material, which is available to authorized users.

Q. Ren $(\bowtie) \cdot$ L. Thöny-Meyer $\cdot$ M. Zinn

Swiss Federal Laboratories for Materials Testing and Research (Empa), Laboratory for Biomaterials, 9014 St. Gallen, Switzerland

e-mail: qun.ren@empa.ch

K. Ruth

Metrohm AG,

Oberdorfstrasse 68 ,

9101 Herisau, Switzerland

\section{Introduction}

The production of enantiomerically pure chemicals has long been considered important in various sectors of the industry including food supplements, pharmaceuticals, cosmetics, fragrances, flavors, and other fine chemicals. In the case of drugs, the presence of an undesirable enantiomer leads to an increase in the dose required, and often also to adverse side effects, such as thalidomide (Roth 2005). Many drugs are now synthesized using chiral synthons provided either by kinetic resolution of racemates, asymmetric synthesis or via the naturally occurring chiral pool (Sheldon 1996). The replacement of conventional-chemical processes by sustainable biotechnological processes is one of the main current tendencies in white biotechnology and biocatalysis (Gavrilescu and Chisti 2005).

$(R)$-hydroxycarboxylic acids (R-HAs) can be widely used as chiral precursors for several reasons: (i) they contain at least two functional groups: a hydroxy group and a carboxy group; (ii) the functional groups can easily be modified chemically; and (iii) a second chiral center can be introduced. The reported compounds using R-HAs as chiral building blocks comprise the macrocyclic component of the antibiotic elaiophylin (Sutter and Seebach 1983), the hydroxyacyl hydrazines in visconsin, a peptide antibiotic (Hiramoto et al. 1971), pharmaceuticals such as captopril and $\beta$-lactams (Ohashi and Hasegawa 1992a, b), and fungicides such as norpyrenophorin and vermiculin (Seuring and Seebach 1978).

It has been reported that R-HAs can be obtained by hydrolysis of biotechnologically synthesized polyhydroxyalkanoates (PHAs) (see review (Chen and Wu 2005a)). PHAs are microbial polyesters, which are accumulated as a carbon and energy storage material under particular environmental conditions such as under nitrogen limitation (Lee 2000; Lenz and Marchessault 2005). PHAs can be produced from 
renewable resources and are biodegradable and biocompatible (Lee 2000; Lenz and Marchessault 2005). It is not within the scope of this article to give a detailed review of PHA biosynthesis and its applications (please see (Chen 2009), an excellent review on PHA). However, it is worth mentioning that despite considerable work on production of PHAs, only few commercial plants have been established in the past few decades (Chen 2009). The drawbacks in commercialization of PHA production could be attributed to the high cost of production, limited microbial strains, difficulty in recovering the polymer, and the presence of impurities during industrial processing. This review mainly focuses on the production of PHA-relevant R-HAs; other types of R-HAs such as lactic acid are not included.

This article briefly reviews possible options for production of R-HAs and their potential applications as illustrated in Fig. 1. Furthermore, perspectives of the biotechnological processes for R-HA production are also discussed.

\section{Methods for R-HA production}

Organic acids constitute a key group among the buildingblock chemicals that can be produced by microbial processes (Sauer et al. 2008). Most of them are natural products of microorganisms, or at least natural intermediates in major metabolic pathways. Because of their functional groups, organic acids are extremely useful as starting materials for the chemical industry. Although chiral hydroxycarboxylic acids (HAs) are attractive compounds with much potential, only few of these compounds are commercially available, such as (R)-3-hydroxybutyric acid (R-3HB). So far, only two enantiomerically pure R-HAs with more than 4 carbon atoms are available on the market: $(R)-3$-hydroxynonanoic acid (supplied by Exclusive Chemistry Ltd, Russia) and (R)-3hydroxytetradecanoic acid (supplied by Wako Pure Chemical Industries Ltd, Japan). A survey of the most interesting $(R)$-3-hydroxycarboxylic acids is given in the Electronic supplementary material. Although the market for R-HAs is currently small, mainly due to high price and limited availability, it can be envisioned that once an economical viable microbial production process for one of these acids is established, the market for it will undoubtedly increase.

Chemical synthesis of R-HAs

\section{De novo synthesis}

The introduction of the chiral center is the challenging step when producing enantiomerically pure R-HAs. Different

\section{Synthesis}

Chemical approach

Biological approach

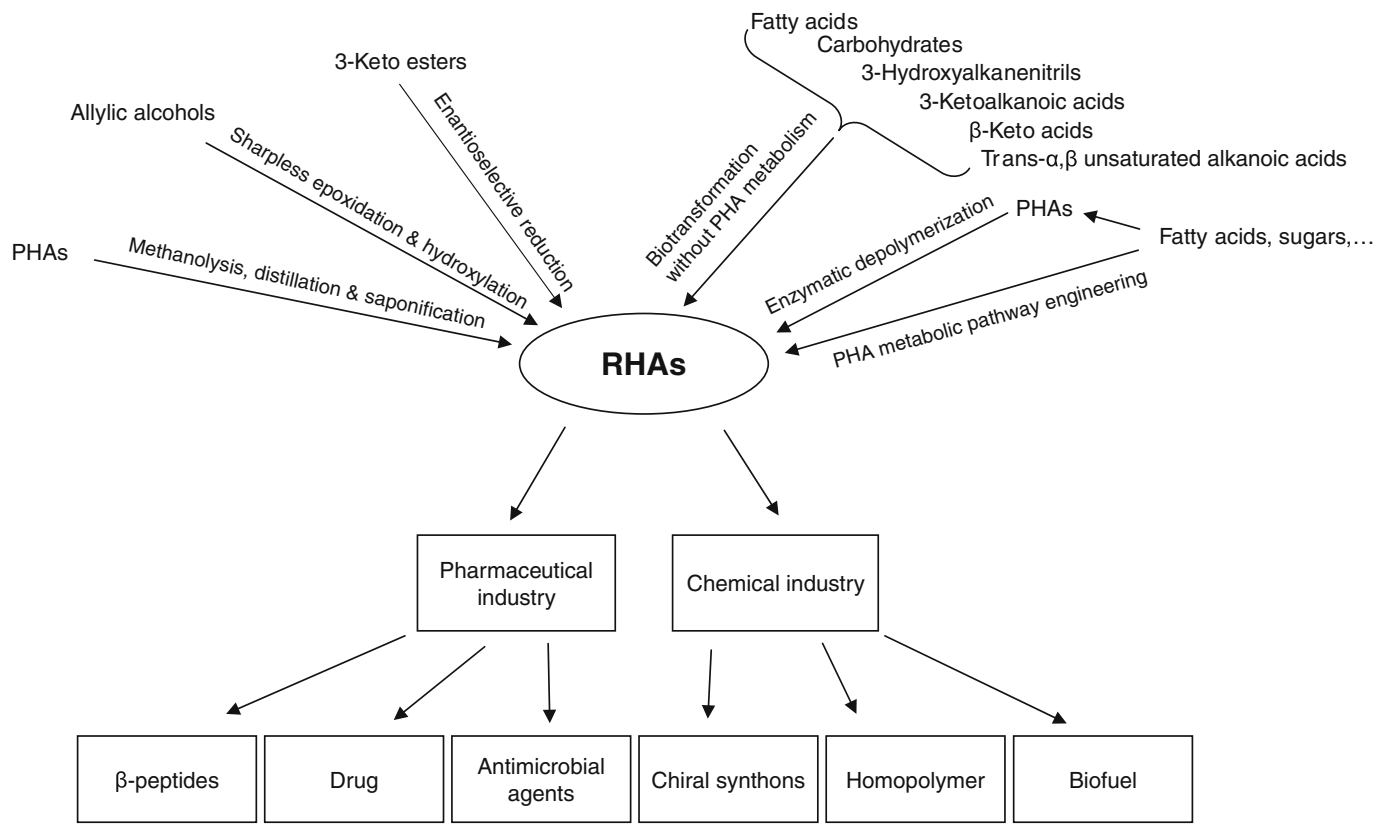

Applications

Fig. 1 Synthesis of R-HAs and their applications 
approaches have been reported. Classical organic synthesis may include stereoselective oxidation through Sharpless' asymmetric epoxidation and consecutive hydroxylation or through Brown's asymmetric allylboration (Brown and Ramachandran 1991). Enantiopure 3-hydroxyesters have been prepared chemically via enantioselective reduction using 3-keto esters as prochiral precursors (Noyori et al. 2004). Recently, Spengler and Albericio (2008) reviewed various possible routes for asymmetric synthesis of enantiopure or enantiomerically enriched $\alpha$-unsubstituted $\beta$-hydroxy acids (3-hydroxycarboxylic acids). General drawbacks of these reactions are the requirement of often expensive, chiral metal-complex catalysts, the contamination of end product with catalysts, and/or the high price of pure substrates. Vigorous reaction conditions such as high pressure, flammable reaction media, or cryogenic conditions are often needed (Brown and Ramachandran 1991; Ikunaka 2003), and the range of possible products is limited. Furthermore, the necessity to synthesize precursor molecules may complicate the synthetic procedure and may reduce the product yield (Nakahata et al. 1982; Wang et al. 1999). Another main disadvantage can be lower enantiomeric excesses (ee) compared to biochemical processes (Sheldon 1996).

\section{Chemical degradation of $\mathrm{PHA}$}

PHAs comprise of monomers with 3-hydroxy, 4-hydroxy, and 5-hydroxy groups. Up to date, about 140 R-HA monomers have been identified (Steinbüchel and Valentin 1995; Sudesh et al. 2000). The length of the side chains varies between 1 and 13 carbon atoms, and a broad range of functional groups can be present, e. g. halogens, phenoxy, acetoxy, phenyl, cyano, and epoxy groups (Steinbüchel and Valentin 1995; Sudesh et al. 2000). All of the monomers are enantiomerically pure and in $(R)$-configuration if they possess a chiral center. Therefore, it was reasoned that various enantiomerically pure R-HAs might be conveniently prepared by depolymerizing biosynthesized PHAs. For example, poly $[(R)-3$-hydroxybutyrate] (PHB) was for the first time suggested to be a source for the chiral pool about 11 years ago (Lee et al. 1999).

Various enantiomerically pure R-HAs can be conveniently prepared by depolymerizing the biosynthesized PHA. A method for producing $\mathrm{R}-3 \mathrm{HB}$ and $(R)$-3-hydroxyvaleric acid (R-3HV) from PHB and poly $[(R)-3$-hydroxybutyrate-co- $(R)$ 3-hydroxyvalerate] (PHBV) by chemical degradation has been reported (Seebach et al. 1993). Lee et al. reported an efficient method for the preparation of R-3HB by acidic alcoholysis of PHB (Lee et al. 2000). de Roo et al. (2002) produced the chiral medium chain length $(\mathrm{mcl})(R)-3-$ hydroxycarboxylic acids via hydrolytic degradation of PHAs synthesized by Pseudomonas putida. PHAs were first degraded by acid methanolysis, and then the obtained RHA methyl esters were distilled into several fractions. Subsequently, the methyl esters were saponified to yield the corresponding $(R)$-3-hydroxycarboxylic acids (de Roo et al. 2002).

\section{Biotransformation}

Biotransformations are enzyme-catalyzed environmentally friendly, regio- and stereoselective processes (Bommarius and Riebel 2004). With regard to the production of R-HAs, microorganisms have been used as biocatalysts to introduce the chiral centers.

\section{De novo biosynthesis}

3-Hydroxyvaleric acid has been prepared by the hydroxylation of valeric acid in fermentation using Candida rugosa (Hasegawa et al. 1981), and a single enantiomer of 3HV (R$3 \mathrm{HV}$ ) was similarly prepared using $P$. putida, Pseudomonas fluorescens, Arthrobacter oxydans, or Arthrobacter crystallopietes (Goodhue and Schaeffe 1971). 3-Hydroxypropionic acid has been produced by fermentative conversion of carbohydrates (Gokarn et al. 2001). The immobilized nitrile hydratase and amidase from Rhodococcus sp. were used to hydrolyze 3-hydroxypropionitrile, 3-hydroxyheptanenitrile, and 3-hydroxynonanenitrile to the corresponding 3hydroxycarboxylic acids at yields of 63,62 , and $83 \%$, respectively (Deraadt et al. 1992); More recently, Hann et al. (2003) used a combination of nitrile hydratase and amidase activities of Comamonas testosteroni 5MGAM4D for the hydrolysis of 3-hydroxyalkanenitriles to 3HAs. It was found that the immobilized $C$. testosteroni 5MGAM4D in consecutive batch reactions was physically robust over 100 recycle reactions, and the enzyme activities of the immobilized cells were also very stable even after 106 days. This process is being used for the production of $100-\mathrm{kg}$ quantities of 3 hydroxyvaleric acid (Hann et al. 2003). However, the chirality of the obtained HAs using nitrile hydratase and amidase was not investigated. If these HAs are racemic mixtures, separation of $R$ and $S$ enantiomers will be needed for their application as synthons.

Several $(R)$ - and $(S)$-3-hydroxyalkanoic acids have been prepared by the enzymatic reduction of the corresponding 3ketoalkanoic acids (Lemieux and Giguere 1951; Utaka et al. 1990). Utaka et al. (1990) reported the production of optically active 3-hydroxy acids by asymmetric reduction of aliphatic short- to long-chain $\beta$-keto acids by fermenting baker's yeast (Sih et al. 1984). $11 \beta$-keto acids, ranging from 3 -oxobutanoic to 3-oxooctanoic acids, were reduced to the corresponding optically pure $\beta$-hydroxy acids, which were isolated as methyl esters. In all cases, the $R$-hydroxy acids were obtained in $\geq 98 \%$ ee, except for 3 -oxobutanoic acid, 
which was converted to the $S$-hydroxy acid with $86 \%$ ee. Inhibition of microbial fermentation was observed for medium chain length oxo acids ranging from 3oxoundecanoic to 3-oxotetradecanoic acids, leading to no reduction of these oxo acids (Sih et al. 1984; Utaka et al. 1990). C6-C12 (S)-3-hydroxyalkanoic acids have been prepared from the corresponding trans- $\alpha, \beta$ unsaturated alkanoic acids by microbial hydration catalyzed by resting cells Mucor sp. (Tahara and Mitzutani 1978). (R)-3Hydroxyhexanoic acids (R-3HHx) and (R)-3-hydroxyheptanoic acid (R-3HP) have been prepared with a mutant strain of C. rugosa (Hasegawa et al. 1983; Ohashi and Hasegawa 1992b).

\section{Enzymatic degradation of purified PHA in vitro}

Up to now, many extracellular PHA depolymerases (ePhaZs) have been identified and characterized (see reviews (Jendrossek and Handrick 2002; Kim et al. 2007)). The ePhaZs partially degrade crystallized or denatured PHA, and the degradation products are typically R-HA monomers and/or dimmers (Jaeger et al. 1995; Jendrossek and Handrick 2002). ePhaZs have been mainly used for surface modification (Numata et al. 2008), while very few studies have been dedicated to R-HA production using ePhaZs. It has been reported that thermophilic Streptomyces sp. MG can hydrolyze purified PHB to R3HB (Calabia and Tokiwa 2006). An added advantage with this strain is its stability at high temperature $\left(50^{\circ} \mathrm{C}\right)$, which would minimize contamination problems. Furthermore, downstream processing is relatively easy since the cells aggregate to form clumps after the fermentation process.

Extracellular lipases from different bacteria were tested for their ability to hydrolyze different types of polyesters to produce HAs (Jaeger et al. 1995). It was found that most lipases were able to hydrolyze polyesters consisting of an omega-hydroxyalkanoic acid such as poly(6-hydroxyhexanoate) or poly(4-hydroxybutyrate). The dimeric ester of hydroxyhexanoate was the main product of enzymatic hydrolysis of polycaprolactone by $P$. aeruginosa lipase. Polyesters containing side chains in the polymer backbone such as PHB and other poly(3-hydroxyalkanoates) were not or were only slightly hydrolyzed by the lipases tested (Jaeger et al. 1995).

\section{Enzymatic degradation of PHA in vivo in wild-type bacteria}

Another attractive approach to obtain R-HAs from PHAs is the in vivo depolymerization. The process utilizes intracellularly located PHA depolymerases for hydrolysis of PHAs (Foster et al. 1996; Foster et al. 1999; Jendrossek and Handrick 2002). It has been efficiently accomplished with natural PHB-synthesizing bacteria to produce R-3HB with a yield of 96\% (g R-3HB/g PHB) (Lee et al. 1999). Appropriate environmental conditions are crucial for this process. Lee et al. (1999) reported that, with Alcaligenes latus (reclassified as Azohydrogenomonas lata (Xie and Yokota 2005)), lowering the environmental $\mathrm{pH}$ to $3-4$ resulted in the highest activity of intracellular PHB depolymerase and blocked the reutilization of R-3HB by the cells.

In order to gain access to more interesting molecules, in vivo depolymerization of mcl-PHA in $P$. putida has been studied (Ren et al. 2005; Ren Zulian et al. 2008; Ruth et al. 2007). PHA containing P. putida cells were suspended in phosphate buffer at different $\mathrm{pH}$ values. At more alkaline $\mathrm{pH}$ values ( $\mathrm{pH}$ 9-11), the degradation of PHA and thus, the release of R-HA monomers were at their best (Ren et al. 2005; Wang et al. 2007). Under such conditions, PHAs containing $R$-3-hydroxyoctanoic acid (R-3HO) and R-3HHx were degraded with an efficiency of over $90 \%(\mathrm{w} / \mathrm{w})$ in $9 \mathrm{~h}$, and the yields of the corresponding monomers were also over $90 \%(\mathrm{w} / \mathrm{w})$. Under the same conditions, unsaturated monomers $R$-3-hydroxy-6-heptenoic acid, $R$-3-hydroxy-8nonenoic acid, and 3-hydroxy-10-undecenoic acid were also produced, although with a lower yield compared with the saturated monomers (Ren et al. 2005).

It seems that PHB depolymerase of $A$. latus and mcl-PHA depolymerase of $P$. putida need different $\mathrm{pH}$ values to have the optimal activities to degrade PHA in vivo: the former at acidic conditions ( $\mathrm{pH} 3-4)$ and the latter at alkaline conditions (pH 9-11) (Lee et al. 1999; Ren et al. 2005). In vitro, all of the so-far characterized PHB depolymerases and mcl-PHA depolymerase of $P$. putida exhibit optimal activities at the alkaline range (de Eugenio et al. 2007; Jendrossek and Handrick 2002). The requirement for different $\mathrm{pH}$ values could be caused by the difference between the intrinsic properties of the PHB depolymerase of A. latus from those of so-far analyzed depolymerases. However, this assumption needs to be verified by further investigation.

\section{R-HA production by metabolic pathway engineering}

Metabolic engineering is a powerful tool to solve defined biotechnological problems, such as enhancing intermediate concentrations or broadening the range of precursors. Vollbrecht et al. have reported to use a double mutant of Ralstonia eutropha (Hydrogenomonas eutropha, Alcaligenes eutropha, Wautersia eutropha, Cupriavidus necator), which is unable to synthesize PHB and to utilize 3-hydroxybutanoate as a substrate, to produce R-3HB (Vollbrecht et al. 1978; Vollbrecht and Schlegel 1978, 1979). About $3.4 \mathrm{~g} / \mathrm{L}$ of R3HB was produced under optimum conditions (Vollbrecht and Schlegel 1979). There have been several reports on metabolic engineering of Escherichia coli for the production of R-3HB (Lee and Lee 2003; Park et al. 2004). When 
recombinant $E$. coli carrying the $R$. eutropha PHB synthetic genes ( $\beta$-ketothiolase (phaA), acetoacetyl-CoA reductase (phaB) and PHB synthetase (phaC)), and the depolymerase gene ( $p h a Z$ ) was cultivated in medium-containing glucose, R-3HB was produced (Lee and Lee 2003). By integration of the PHB biosynthetic genes into the chromosome of E. coli together with providing a plasmid containing phaZ, R-3HB could be efficiently produced without plasmid instability in the absence of antibiotics (Lee and Lee 2003).

It was also reported that R-HAs can be produced by recombinant organisms directly, without going through the PHA hydrolysis process (Chen and Wu 2005b; Gao et al. 2002; Zhao et al. 2003). For example, recombinant $E$. coli HB101 harboring PHB precursor genes phaA and phaB of $R$. eutropha was able to produce more than $1 \mathrm{~g} / \mathrm{L}$ of $3 \mathrm{HB}$ monomer extracellularly after $48 \mathrm{~h}$ of fermentation (Wu et al. 2003). Heterologous expression of $(R)$-3-hydroxydecanolACP:CoA transacylase gene (phaG) of P. putida in E. coli HB101 led to extracellular production of 3-hydroxydecanoic acid (3HD) from fructose with a yield of $0.587 \mathrm{~g} / \mathrm{L}$. Simultaneous expression of both $p h a G$ and tes $B$ (encoding thioesterase II of E. coli) in E. coli HB101 increased 3HD production compared with the expression of $p h a G$ alone under identical conditions (Zheng et al. 2004). Recently, TesB was found to be able to facilitate $3 \mathrm{HB}$ production (Liu et al. 2007). E. coli BW25113 harboring phaA, phaB, and tes $B$ genes produced approximately $4 \mathrm{~g} / \mathrm{L} 3 \mathrm{HB}$ in shake flask culture within $24 \mathrm{~h}$ with glucose as a carbon source (Zheng et al. 2004). The produced HAs mentioned here were not analyzed for their chiral configuration. However, due to the enzymatic activities of $\mathrm{PhaB}$ and $\mathrm{PhaG}$, the obtained HAs are very likely to be R-HAs.

A biosynthetic pathway for the production of $(S)-3-$ hydroxybutyric acid (S-3HB) from glucose was established in recombinant $E$. coli by introducing phaA from $R$. eutropha, the (S)-3-hydroxybutyryl-CoA dehydrogenase gene from $R$. eutropha, or Clostridium acetobutylicum ATCC824, and the 3-hydroxyisobutyryl-CoA hydrolase gene from Bacillus cereus ATCC14579 (Lee et al. 2008). The recombinant $E$. coli could synthesize enantiomerically pure $\mathrm{S}-3 \mathrm{HB}$ in a concentration up to $10.3 \mathrm{~g} / \mathrm{L}$; the $\mathrm{S}-3 \mathrm{HB}$ productivity was $0.21 \mathrm{~g} / \mathrm{L} / \mathrm{h}$. It was also reported that the chirality of $3 \mathrm{HB}$ could be controlled by metabolic pathway engineering of $E$. coli strains (Tseng et al. 2009). The engineered strain achieved titers of enantiopure R-3HB and $\mathrm{S}-3 \mathrm{HB}$ as high as $2.92 \mathrm{~h} / \mathrm{L}$ and $2.08 \mathrm{~g} / \mathrm{L}$, respectively, in shake flask cultures within 2 days (Tseng et al. 2009).

1,3-Propanediol dehydrogenase (DhaT) and aldehyde dehydrogenase (AldD) from $P$. putida KT2442 are capable of transforming 1,4-butanediol $(1,4-\mathrm{BD})$ to 4 hydroxybutyrate (4HB) (Zhang et al. 2009a). Thus, Aeromonas hydrophila 4AK4, E. coli S17-1, or P. putida KT2442 harboring dhaT and aldD were used to produce
4HB. Recombinant A. hydrophila 4AK4 containing dhaT and aldD was able to produce over $10 \mathrm{~g} / \mathrm{L} 4 \mathrm{HB}$ from $20 \mathrm{~g} / \mathrm{L} 1,4-\mathrm{BD}$ after $52 \mathrm{~h}$ of cultivation in a $6-\mathrm{L}$ fermenter (Zhang et al. 2009a). Recently, an economical, high-titer method for the production of 4-hydroxyvalerate $(4 \mathrm{HV})$ and 3-hydroxyvalerate (3HV) from the inexpensive and renewable carbon source levulinic acid was developed (Martin and Prather 2009). These hydroxyvalerates were produced by periodically feeding levulinate to $P$. putida KT2440 expressing the tes $B$ gene from $E$. coli.

Sandoval et al. (2005) reported that 3-hydroxy- $n$-phenylalkanoic acids can be produced by a genetically engineered strain of $P$. putida $\mathrm{U}$. Overexpression of the gene encoding the poly(3-hydroxy- $n$-phenylalkanoate) (PHPhA) depolymerase (phaZ) in P. putida $\mathrm{U}$ avoids the accumulation of these polymers as storage granules. The genetically engineered strain of $P$. putida $\mathrm{U}$ ( $\triangle f a d B A ;$ phaZ on plasmid) can efficiently convert different $n$-phenylalkanoic acids into their corresponding 3-hydroxy- $n$-phenylalkanoic acids derivatives, and it excretes these compounds into the culture broth. However, the obtained 3-hydroxy- $n$-phenylalkanoic acids are racemic mixtures (Sandoval et al. 2005).

Medium chain length R-3HHx and R-3HO were produced by overexpressing the PHA depolymerase gene (phaZ) of P. putida KT2442, together with the putative long-chain fatty acid transport gene ( $f a d L)$ of $P$. putida KT2442 and acyl-CoA synthetase gene ( $f a d D)$ of $E$. coli MG1655 in P. putida KT2442 (Yuan et al. 2008). In a 48$\mathrm{h}$ fed-batch fermentation process conducted in a 6-L fermenter with 3-L sodium octanoate mineral medium, $5.8 \mathrm{~g} / \mathrm{L}$ of extracellular R-3HHx and R-3HO was obtained in the fermentation broth (Yuan et al. 2008). P. putida KTOY01, a PHA synthesis operon knockout mutant, was used for the direct production of medium chain length RHAs without going through PHA synthesis (Chung et al. 2009). R-3HHx, R-3HO, R-3HD, and (R)-3-hydroxydodecanoate (R-3HDD) were produced by $P$. putida KTOY01 carrying tes $B$ using dodecanoate as a sole carbon source.

\section{Potential applications of R-HAs}

Since R-HAs contain a chiral center and two easily modified functional groups $(-\mathrm{OH}$ and $-\mathrm{COOH})$, they are valuable synthons, i.e., they may serve as starting materials for the synthesis of fine chemicals such as antibiotics, vitamins, flavors, fragrances, and pheromones (Chiba and Nakai 1985; Ohashi and Hasegawa 1992a; Seebach et al. 2001).

Chiral synthons for organic synthesis

As R-HAs are not readily available on the market and their classical synthesis is rather tedious, only few synthetic 
routes using such reactants as starting material have been reported. The $\alpha, \beta$-unsaturated $\delta$-lactone $(R)$-massoialactone has been known as a constituent of natural medicine for many centuries and has been isolated from Cryptocarya massoia, as well as from jasmine flowers (Kaiser and Lamparsky 1976). Like many aliphatic $\delta$-lactones it occurs in several food flavors and essential oils, which are widely used due to their specific odor impression and lowthreshold concentration. Touati et al. succeeded with the synthesis of massoialactone using a rutheniumarylphosphine catalyst $\left[\mathrm{RuBr}_{2}((\mathrm{R})-\mathrm{SYNPHOS})\right]$ to produce the intermediate $(R)$-3-hydroxyoctanoate through asymmetric hydrogenation (Touati et al. 2006). Chiral synthesis of another $\delta$-lactone, 3,5-dihydroxydecanoic acid, via $(R)$-3hydroxyoctanoate has also been reported (Satō 1987). Both syntheses use rather expensive complex metal catalysis to introduce the chiral center. Hence, easy accessibility of RHAs would simplify these two and many other syntheses of saturated and unsaturated aliphatic $\beta$-lactones, which are interesting bioactive natural products.

Gloeosporone, containing a 14-membered macrolide, is an autoinhibitor of spore germination, and ( $R$ )-3-hydroxyoctanoate methyl ester can be used as reactant in its synthesis (Schreiber et al. 1988). In this multistage synthesis, the method of choice for producing this compound is an asymmetric reduction of $\beta$-keto esters to cope with stereochemical problems. A Ru(II)-BINAP catalyst has been developed for introducing the proper chiral conformation (Noyori et al. 1987). Challenging metal-catalyzed reactions can be avoided when starting with $(R)$-3-hydroxyoctanoate from a bacterial source.

Certain divinyl ether fatty acids inhibit mycelial growth and spore germination in certain fungi (Graner et al. 2003). R-HAs can serve as chiral precursors for the synthesis of those compounds, e.g., $(R)$-3-hydroxyheptanoate was reported to be obtained by several crystallization steps from carcinogenic carbon tetrachloride for this purpose (Hamberg 2005).

Linear-condensed triquinane sesquiterpenes are constituents of essential oils in plants and of great economical interest. Starting materials such as bicyclo[3.2.0]hept-3-en6-ones (Marotta et al. 1994a) or tetrahydro-2H-cyclopenta [b]furan-2-ones (Marotta et al. 1994c) can be synthesized with $(R)$-3-hydroxyhept-6-enoate as reactant. $(R)$-3-hydroxyhept-6-enoate is also a precursor for eremophilan carbolactones (Hayakawa et al. 1988), which are valuable compounds for drug synthesis and also known in traditional Chinese medicine. These compounds have been shown to have positive effects on blood circulation and rheumatism and some were found to exhibit antimicrobial activities (Zhang et al. 2004).

In fact, there are many bioactive and pharmaceutically interesting molecules known containing R-HAs as sub- structures. Hence, the accessibility of these chiral acids as building blocks might open new synthetic routes towards such important compounds. Table 1 illustrates the versatility of possible applications using R-HAs. In Table 1, only R-HAs directly involved in the subsequent reactions have been considered. Taking all possible biotechnologically producible R-HAs into account, the number of potential synthetic pathways towards pharmaceutically interesting compounds increases enormously.

Homopolymers and tailor-made block copolymers

A special application of chiral $3 \mathrm{HA}$ is the possibility to create tailor-made polymers when using them as monomers in a condensation reaction. As in most polyester syntheses, the challenge is to reach high molecular weights. Various methods can be applied to condense R-HAs, in order to build up polyesters. Crucial features of those reactions are the activation of the carboxylic group and the removal of water to shift the equilibrium to the polyester product side. R-HAs can be activated by dicyclohexylcarbodiimide (DCC), $p$-toluenesulfonyl chloride (TosCl), or 2,4,6-triisopropylbenzenesulfonyl chloride (TPS) in anhydrous solvents at $25^{\circ} \mathrm{C}$ to start the polymerization reaction (Hattori et al. 1978). Triethyl amine $\left(\mathrm{NEt}_{3}\right)$ has already been described to trigger polymerization of $\mathrm{HA}$ at $0{ }^{\circ} \mathrm{C}$ (Arslan et al. 2004). Boiling $\mathrm{HCl}$ or concentrated $\mathrm{H}_{2} \mathrm{SO}_{4}$ can also be used to catalyze the release of water (Becker et al. 2001). For conversion via titanium(IV) isopropoxide, a temperature of $140{ }^{\circ} \mathrm{C}$ and reduced pressure are necessary (Kobayashi and Hori 1993). Seebach et al. obtained PHB from its monomers by adding $\mathrm{COCl}_{2}$ and pyridine at $-78{ }^{\circ} \mathrm{C}$ (Lengweiler et al. 1996; Seebach and Fritz 1999). So far, only racemic starting materials or R-3HB have been used for the above described reactions.

Zhang et al. (2009a) recently reported that R-4HB could be produced by recombinant bacteria harboring dhaT and aldD from 1,4-butanediol. Fermentation broth containing $4 \mathrm{HB}$ was further used for production of homopolymer poly(4-hydroxybutyrate) $[\mathrm{P}(4 \mathrm{HB})]$ and copolymers poly(3-hydroxybutyrate-co-4-hydroxybutyrate) $[\mathrm{P}(3 \mathrm{HB}-4 \mathrm{HB})]$ by recombinant $E$. coli $\mathrm{S} 17-1$ or $R$. eutropha H16 (Zhang et al. 2009a).

Since (R)-3-hydroxycarboxylic acids from bacterial sources have $100 \%(R)$-configuration, they always result in polyesters composed of isotactic macromolecules. The process of in vivo depolymerization of PHA to obtain RHAs and their consecutive polymerization might seem circuitous. However, it may open a new way to the synthesis of a totally isotactic class of homo-polyesters with special characteristics and unique properties, especially considering that PHAs synthesized in bacteria are always co-polyesters, with the exception of PHB and poly(3- 
Table 1 Potential applications for selected R-HAs as synthons

\begin{tabular}{|c|c|c|}
\hline R-HAs & Potential synthon for & Reference \\
\hline \multirow[t]{2}{*}{$(R)$-3-hydroxyundec-10-enoate } & $\begin{array}{l}\text { Inhibitor of cholesterol synthesis, effects } \\
\text { 3-hydroxy-3-methyl-glutaryl (HMG) CoA synthetase }\end{array}$ & Dirat et al. (1998) \\
\hline & $\begin{array}{l}\text { Precursor of L-659,699 (inhibitor of cholesterol } \\
\text { biosynthesis) }\end{array}$ & Chiang et al. (1989) \\
\hline \multirow[t]{8}{*}{$(R)$-3-hydroxy-undecanoate } & Depsipeptides (antibiotic/antifungal) & Nihei et al. (2005); Wohlrab et al. (2007) \\
\hline & (-)-tetrahydrolipstatin (anti-obesity drug) & $\begin{array}{l}\text { Pons and Kocienski (1989); Sarabia and } \\
\text { Chammaa (2005) }\end{array}$ \\
\hline & Lipid A mimic (immunobiological) & Martin et al. (2006) \\
\hline & Stevastelins B and B3 & Sarabia and Chammaa (2005) \\
\hline & Sulfobacin A & $\begin{array}{l}\text { Gupta et al. (2004); Irako and Shioiri (1998); } \\
\text { Labeeuw et al. (2004) }\end{array}$ \\
\hline & Globomycin (antibiotic, signal peptidase II inhibitor) & Kiho et al. (2003a); Kiho et al. (2003b, 2004) \\
\hline & Pseudomycin & Rodriguez et al. (2001) \\
\hline & Topostins B567 and D654 & Irako and Shioiri (1998) \\
\hline \multirow[t]{2}{*}{ (R)-3-hydroxy-nonanoate } & Globomycin analogs (antibiotic) & Kiho et al. (2004) \\
\hline & $\begin{array}{l}(R) \text {-2-benzylcyclohexanone (precursor of natural } \\
\text { products) }\end{array}$ & Katoh et al. (1994) \\
\hline \multirow[t]{2}{*}{ (R)-3-hydroxyoctanoate } & $\begin{array}{l}\text { Simvastatin (antihypercholesterolemic, inhibitor } \\
\text { of HMG-CoA reductase }\end{array}$ & Lee and Lee (2004); Morgan and Burk (2005) \\
\hline & Viscosin & Hiramoto (1971) \\
\hline \multirow[t]{10}{*}{ (R)-3-hydroxyhept-6-enoate } & Potent HMG CoA reductase inhibitor FR901512 & Inoue and Nakada (2007) \\
\hline & Rosuvastatin calcium, a HMG CoA reductase inhibitors & Zlicar (2007) \\
\hline & $\alpha, \beta$-disubstituted $\beta$-lactones & Wu and Sun (2005) \\
\hline & Sphingofungin D (antifungal) & $\begin{array}{l}\text { Mori and Otaka (1994); Vanmiddlesworth } \\
\text { et al. (1992) }\end{array}$ \\
\hline & Sphingofungin F (antifungal) & Kobayashi et al. (1997) \\
\hline & $\begin{array}{l}\text { Precursor of } \beta \text {-lactams for synthesis } \\
\text { of carbacephems (class of antibiotics) }\end{array}$ & Crocker and Miller (1995) \\
\hline & Ebelactone $\mathrm{A}$ and $\mathrm{B}$ ( $\beta$-lactone enzyme inhibitor) & Paterson and Hulme (1995) \\
\hline & Bicycloheptenones & Marotta et al. (1994b) \\
\hline & Cyclosporine A derivatives (immunosuppressive) & $\begin{array}{l}\text { Aebi et al. (1990); Colucci et al. (1990); Lynch } \\
\text { et al. (1987); Rich et al. (1989); Schmidt } \\
\text { and Siegel (1987); Schreiber et al. (1988) }\end{array}$ \\
\hline & $(S)$-citronellol & Hirama et al. (1985) \\
\hline \multirow[t]{2}{*}{ (R)-3-hydroxyheptanoate } & Anachelin (siderophore of Anabaena cylindrica) & Ito et al. (2004) \\
\hline & Pravastatin (atherosclerosis/hypercholesteremia agent) & Keri et al. (2007) \\
\hline (R)-3-hydroxyhexanoate & $\begin{array}{l}\text { Analogs of laulimalide (paclitaxel like } \\
\text { antimicrotubule agent) }\end{array}$ & Faveau et al. (2006) \\
\hline
\end{tabular}

hydroxyphenylvalerate). It is also feasible to synthesize block or graft copolymers using several types of different 3hydroxycarboxylic acids as monomeric building blocks.

Synthesis of $\beta$-amino acids

Park et al. (2001) have reported previously that optically active ethyl $\beta$-aminobutyrate can be prepared from R-HA. Ethyl R-3HB was treated with $p$-toluenesulfonyl chloride and sodium azide, leading to the formation of the corresponding azido ester, which was then converted to the $\beta$-amino acid by indium-mediated reduction. The overall reaction proceeded with inversion of configuration. This methodology is also expected to be applicable to the preparation of primary amines from the corresponding alcohols (Park et al. 2001). Peptides containing $\beta$-amino acids are generally more stable to enzymatic hydrolysis due to the inability of proteases and peptidases to cleave the amide bonds adjacent to the $\beta$-amino acid (Park et al. 2001; Seebach et al. 2001). Since $\beta$-peptides are stable towards peptidases, they can be used as scaffolds for peptide mimics (Chen and Wu 2005b). Certain $\beta$-peptides have antibacterial, antiproliferative, or hemolytic properties (Chen and Wu 2005b). 
Medical applications

It is known that R-3HB is ubiquitous in all kinds of cells (Chen 2009). Thus, one of the biggest advantages for R$3 \mathrm{HB}$ is that it is well-tolerated by humans, i.e., it is biocompatible. Recently, R-3HB has been employed to treat traumatic injuries such as hemorrhagic shock, extensive burns, myocardial damage, and cerebral hypoxia, anoxia, and ischemia (Massieu et al. 2003; Tieu et al. 2003; Zou et al. 2009). It was also shown that $3 \mathrm{HB}$ oligomers provide energy and show good penetration and rapid diffusion in peripheral tissue; hence, they could be an energy substrate for injured patients (Tasaki et al. 1999). $\mathrm{R}-3 \mathrm{HB}$ could also serve as energy substrate in increasing cardiac efficiency and thus, prevents brain damage (Kashiwaya et al. 2000). There is also evidence that R$3 \mathrm{HB}$ can correct defects in mitochondrial energy generation in the heart (Katayama et al. 1994).

Furthermore, R-3HB has been found to be able to reduce the death rate of the human neuronal cell model culture for Alzheimer's and Parkinson's diseases and to ameliorate the appearance of corneal epithelial erosion through suppression of apoptosis (Kashiwaya et al. 2000); R-3HB methyl ester was also found to dramatically improve the memory of mice (Zou et al. 2009).

Recently, R-3HB was clearly demonstrated to have a positive effect on the growth of osteoblasts in vitro and an anti-osteoporosis effect in vivo (Zhao et al. 2007). It was found that R-3HB increased serum alkaline phosphatase activity and calcium deposition, decreased serum osteocalcin, prevented bone mineral density reduction resulting from ovariectomization, leading to enhanced femur maximal load and bone deformation resistance, as well as improved trabecular bone volume (Zhao et al. 2007).

\section{Antimicrobial agents}

Fatty acids have been known as antimicrobial agents for more than 80 years. They function as surface-active anionic detergents (Kodicek 1949). Once the fatty acid has been adsorbed by cells, the inhibitory effect might be brought about by concomitant changes in cell permeability (Nieman 1954). It has been reported that the length of the carbon chain plays an important role in the antimicrobial activity (Nieman 1954). Some R-HAs exhibit antimicrobial or antiviral effects, while other R-HAs do not.

Sandoval et al. (2005) reported that (R)-3-hydroxy- $n$ phenylalkanoic acid can effectively attack Listeria monocytogenes, which is an ubiquitous microorganism, and able to multiply at refrigeration temperatures and is resistant to both high temperature and low $\mathrm{pH}$. R-3HB has been shown to exhibit some antimicrobial, insecticidal, and antiviral activities (Chen and Wu 2005b; Shiraki et al. 2006).
Recently, Ruth et al. (2007) tested medium chain length R-HAs for their antimicrobial activities. It was found that R-3HO, (R)-3-hydroxy-8-nonenoic acid, and ( $R$-3-hydroxy-10-undecenoic acid exhibited much higher activities against the growth of Listeria species and Staphylococcus aureus than their racemic mixtures or their nonhydroxylated free fatty acid counterparts (Ruth et al. 2007).

\section{Biofuel}

Recently, Zhang et al. (2009b) proposed R-HA methyl esters (R-HAME) as a new type of biofuel. They found that the combustion heat of blended fuels, namely R-HAMEdiesel or R-HAME - gasoline, were lower than that of pure diesel or gasoline but were usable as fuels. It was roughly estimated that the production costs of R-HAME-based biofuels from waste resources including waste water and activated sludge should be around US\$1,200/ton (Zhang et al. 2009b). It was claimed that R-HAME-based biofuel production from waste water or from activated sludge enjoys the advantages of waste water treatment accompanied by energy generation.

\section{Perspectives of biotechnological production of R-HAs}

For biotechnological production of R-HAs on a large scale, it is important to not only consider yield, product concentration, and productivity, but also the cost of substrates and downstream processing, which are crucial constraints for a process to become economically viable. Often a bioprocess optimized for production as established in academia does not necessarily represent the most favorable conditions when viewed from an economic standpoint. High substrate costs can abolish the advantage of high yield, or high purification cost can limit any cost advantages of an inexpensive carbon source. Clearly, these factors are interrelated.

At present, large research efforts have been dedicated to the use of lignocellulosic biomass. This is highly abundant and significantly cheaper than refined sugar, making it an interesting substrate for microbial production processes in general. PHAs have been reported to be produced from such biomass (Li et al. 2007; Munoz and Riley 2008; Yu and Chen 2008; Yu and Stahl 2008). However, one has to consider that lignocellulose comprises different types of substances that might interfere with the bioprocess and that require an extensive downstream processing, which would add to the final costs. Further investigations are needed to clarify these issues.

An integral part of process optimization must be the reduction of the purification costs, but these are highly interconnected with biological and economic factors. 
Purification costs are higher with less-purified substrates and by-products can also constitute an important problem. To ensure that minimum effort is required for purification, the preceding bioprocess should avoid accumulation of impurities as much as possible from the beginning of the process. Ruth et al. (2007) reported a biotechnological process to produce R-HAs. Here, chromatography was used to purify R-HAs. To be economically viable, further improvement of this process must be brought at the step of R-HA purification. Only under such a condition can this biotechnological process become attractive for industrial production of R-HAs.

To gain the most from the producing organism, the process must be optimized taking into account biological, as well as economic constraints. Viewing the bioprocess for R-HA production objectively, it appears that biomass accumulation somehow wastes the carbon source. Instead of being converted into PHAs (and subsequently R-HAs), the substrate is converted into biomass. A number of studies are therefore related to the idea of uncoupling biomass accumulation from PHA production (Sun et al. 2009).

Very often there are problems that simply cannot be solved by the proper selection of the production organism and bioprocess engineering. The organisms themselves must be altered in a rational way to be able to cope with the constraints of cost-effective production. For example, lignocellulosic biomass is an attractive substrate for PHA/ R-HA production. However, few microorganisms can metabolize pentose sugars derived from these raw materials (Lopes et al. 2009; Tian et al. 2009). Therefore, metabolic engineering of strains might enable the efficient utilization of this biomass. On the other hand, although the modification of defined pathways in an organism is usually straightforward, one should realize that only a few of these approaches have been successfully used in industrial applications. One of the reasons is exposure of the microorganisms to a variety of stresses. Stress requires the cell to dedicate more effort to maintaining its natural equilibrium. This greater effort leads to several consequences, including a change in metabolic activity, lower growth rate, lower viability, and lower productivity (Sauer et al. 2008). Strain robustness, which is the ability of the microorganism to withstand the production environment, is therefore a key factor determining whether a bioprocess will be successful and industrially viable.

For a biotechnological process for R-HA production to be competitive at large scale, the following aspects have to be taken into account: substrate cost, product purification, and strain fitness. These aspects are interrelated, e.g., the choice of substrate cannot be made without considering downstream processing or strain fitness, the choice of strain influences downstream processing due to by-products and also influences the choice for substrates. Only when these aspects are properly addressed does the biotechnological process has the potential to be economically viable for industrial production of R-HAs. Once such processes are established, the applications of these chiral compounds in chemical and pharmaceutical industries will be possible.

Acknowledgment Authors thank Dr. Micheal Fairhead and Dr. Julian Ihssen for reading the manuscript.

Open Access This article is distributed under the terms of the Creative Commons Attribution Noncommercial License which permits any noncommercial use, distribution, and reproduction in any medium, provided the original author(s) and source are credited.

\section{References}

Aebi JD, Deyo DT, Chong QS, Guillaume D, Dunlap B, Rich DH (1990) Synthesis, conformation, and immunosuppressive activities of 3 analogs of cyclosporine-a modified in the 1-position. J Med Chem 33:999-1009

Arslan H, Mentes A, Hazer B (2004) Synthesis and characterization of diblock, triblock, and multiblock copolymers containing poly(3hydroxybutyrate) units. J Appl Polym Sci 94:1789-1796

Becker GOH, Berger W, Domschke G (2001) Organikum organischchemisches Grundpraktikum. Wiley-VCH, Weinheim

Bommarius AS, Riebel BR (2004) Biocatalysis-fundamentals and applications. Wiley-VCH, Weinheim

Brown HC, Ramachandran PV (1991) The boron approach to asymmetric-synthesis. Pure Appl Chem 63:307-316

Calabia BP, Tokiwa Y (2006) A novel PHB depolymerase from a thermophilic Streptomyces sp. Biotechnol Lett 28:383-388

Chen GQ (2009) A microbial polyhydroxyalkanoates (PHA) based bio- and materials industry. Chem Soc Rev 38:2434-2446

Chen GQ, Wu Q (2005a) The application of polyhydroxyalkanoates as tissue engineering materials. Biomaterials 26:6565-6578

Chen GQ, Wu Q (2005b) Microbial production and applications of chiral hydroxyalkanoates. Appl Microbiol Biotechnol 67:592599

Chiang YCP, Yang SS, Heck JV, Chabala JC, Chang MN (1989) Total synthesis of L-659, 699, a novel inhibitor of cholesterolbiosynthesis. J Org Chem 54:5708-5712

Chiba T, Nakai T (1985) A synthetic approach to (+)-thienamycin from methyl $(R)$-3-hydroxybutanoate. A new entry to $(3 R, 4 R)-3-[(R)-1$ hydroxyethyl]-4-acetoxy-2-azetidinone. Chem Lett 14:651-654

Chung A, Liu Q, Ouyang SP, Wu Q, Chen GQ (2009) Microbial production of 3-hydroxydodecanoic acid by pha operon and fadBA knockout mutant of Pseudomonas putida KT2442 harboring tesB gene. Appl Microbiol Biotechnol 83:513-519

Colucci WJ, Tung RD, Petri JA, Rich DH (1990) Synthesis of D-lysine8-cyclosporine A-further characterization of Bop-Cl in the 2-7 hexapeptide fragment synthesis. J Org Chem 55:2895-2903

Crocker PJ, Miller MJ (1995) Oxidative free-radical cyclization as a method for annulating $\beta$-lactams: syntheses of functionalized carbacephams. J Org Chem 60:6176-6179

de Eugenio LI, Garcia P, Luengo JM, Sanz JM, San Roman J, Garcia JL, Prieto MA (2007) Biochemical evidence that phaZ gene encodes a specific intracellular medium chain length polyhydroxyalkanoate depolymerase in Pseudomonas putida KT2442 - characterization of a paradigmatic enzyme. J Biol Chem 282:4951-4962

de Roo G, Kellerhals MB, Ren Q, Witholt B, Kessler B (2002) Production of chiral $R$-3-hydroxyalkanoic acids and $R$-3-hydroxy alkanoic acid methylesters via hydrolytic degradation of polyhy- 
droxyalkanoate synthesized by pseudomonads. Biotech Bioeng 77:717-722

Deraadt A, Klempier N, Faber K, Griengl H (1992) Chemoselective enzymatic-hydrolysis of aliphatic and alicyclic nitriles. J Chem Soc Perkin Trans 1(1):137-140

Dirat O, Kouklovsky C, Langlois Y (1998) Oxazoline N-oxidemediated [2+3] cycloadditions: application to a total synthesis of the hypocholesterolemic agent 1233A. J Org Chem 63:6634 6642

Faveau C, Mondon M, Gesson JP, Mahnke T, Gebhardt S, Koert U (2006) Synthetic studies on a phenyl-laulimalide analogue. Tetrahedron Lett 47:8305-8308

Foster LJR, Stuart ES, Tehrani A, Lenz RW, Fuller RC (1996) Intracellular depolymerase and polyhydroxyoctanoate granule integrity in Pseudomonas oleovorans. Int J Biol Macromol 19:177-183

Foster LJR, Lenz RW, Fuller RC (1999) Intracellular depolymerase activity in isolated inclusion bodies containing polyhydroxyalkanoates with long alkyl and functional substituents in the side chain. Int J Biol Macromol 26:187-192

Gao HJ, Wu QN, Chen GQ (2002) Enhanced production of D-(-)-3hydroxybutyric acid by recombinant Escherichia coli. FEMS Microbiol Lett 213:59-65

Gavrilescu M, Chisti Y (2005) Biotechnology - a sustainable alternative for chemical industry. Biotechnol Adv 23:471-499

Gokarn RR, Selifonova OV, Jessen HJ, Steven JG, Selmer T, Buckel W (2001) 3-Hydroxypropionic acid and other organic compounds. Patent PCT/US2001/043607

Goodhue CT, Schaeffe JR (1971) Preparation of L $(+)$ betahydroxyisobutyric acid by bacterial oxidation of isobutyric acid. Biotechnol Bioeng 13:203-214

Graner G, Hamberg M, Meijer J (2003) Screening of oxylipins for control of oilseed rape (Brassica napus) fungal pathogens. Phytochemistry 63:89-95

Gupta P, Naidu SV, Kumar P (2004) A practical enantioselective synthesis of massoialactone via hydrolytic kinetic resolution. Tetrahedron Lett 45:849-851

Hamberg M (2005) Hidden stereospecificity in the biosynthesis of divinyl ether fatty acids. FEBS J 272:736-743

Hann EC, Sigmund AE, Fager SK, Cooling FB, Gavagan JE, Ben-Bassat A, Chauhan S, Payne MS, Hennessey SM, DiCosimo R (2003) Biocatalytic hydrolysis of 3-hydroxyalkanenitriles to 3hydroxyalkanoic acids. Adv Synth Catal 345:775-782

Hasegawa J, Hamaguchi S, Ogura M, Watanabe K (1981) Production of beta-hydroxycarboxylic acids from aliphatic carboxylic acids by microorganisms. J Ferment Technol 59:257-262

Hasegawa J, Ogura M, Kanema H, Kawaharada H, Watanabe K (1983) Production of D-beta-hydroxycarboxylic acids from the corresponding carboxylic acids by a mutant of Candida rugosa. J Ferment Technol 61:37-42

Hattori M, Takai H, Kinoshita M (1978) Syntheses and condensation polymerizations of 3-hydroxybutyric acid-derivatives of pyrimidine-bases. Macromol Chem Phys 179:905-913

Hayakawa K, Nagatsugi F, Kanematsu K (1988) Total synthesis of (+)-4-oxo-5, 6, 9, 10-tetradehydro-4, 5-secofuranoeremophilane5,1 -carbolact one via novel lactone construction through allene intramolecular cyclo-addition. J Org Chem 53:860-863

Hirama M, Noda T, Ito $S$ (1985) Convenient synthesis of $(S)$ citronellol of high optical purity. J Org Chem 50:127-129

Hiramoto M, Okada K, Nagai S (1971) The structure of viscosin, a peptide antibiotic - syntheses of D-3-hydroxyacyl-L-leucine hydrazides related to viscosin. Chem Pharm Bull 19:13081314

Ikunaka M (2003) A process in need is a process indeed: scalable enantioselective synthesis of chiral compounds for the pharmaceutical industry. Chem Eur J 9:379-388
Inoue M, Nakada M (2007) Structure elucidation and enantioselective total synthesis of the potent HMG-CoA reductase inhibitor FR901512 via catalytic asymmetric Nozaki-Hiyama reactions. J Am Chem Soc 129:4164-4165

Irako N, Shioiri T (1998) Total synthesis of sulfobacin A (Flavocristamide B). Tetrahedron Lett 39:5793-5796

Ito Y, Ishida K, Okada S, Murakami M (2004) The absolute stereochemistry of anachelins, siderophores from the cyanobacterium Anabaena cylindrica. Tetrahedron 60:9075-9080

Jaeger K, Steinbüchel A, Jendrossek D (1995) Substrate specificities of bacterial polyhydroxyalkanoate depolymerases and lipasesbacterial lipases hydrolyze poly(omega-hydroxyalkanoates). Appl Environ Microbiol 61:3113-3118

Jendrossek D, Handrick R (2002) Microbial degradation of polyhydroxyalkanoates. Annu Rev Microbiol 56:403-432

Kaiser R, Lamparsky D (1976) Lactone of 5-hydroxy-cis-2-cis-7decadienic acid and other lactones from essential oils of Polianthes tuberosa L flowers. Tetrahedron Lett 17:1659-1660

Kashiwaya Y, Takeshima T, Mori N, Nakashima K, Clarke K, Veech RL (2000) D- $\beta$-Hydroxybutyrate protects neurons in models of Alzheimer's and Parkinson's disease. Proc Natl Acad Sci U S A 97:5440-5444

Katayama M, Hiraide A, Sugimoto H, Yoshioka T, Sugimoto T (1994) Effect of ketone bodies on hyperglycemia and lactic acidemia in hemorrhagic stress. J Parenter Enteral Nutr 18:442-446

Katoh O, Sugai T, Ohta H (1994) Application of microbial enantiofacially selective hydrolysis in natural product synthesis. Tetrahedron-Asymmetry 5:1935-1944

Keri V, Szabo C, Arvai E, Aronhime J (2007) Novel forms of pravastatin sodium. Patent US2005288370

Kiho T, Nakayama M, Kogen H (2003a) Total synthesis and NMR conformational study of signal peptidase II inhibitors, globomycin and SF-1902 A(5). Tetrahedron 59:1685-1697

Kiho T, Nakayama M, Yasuda K, Miyakoshi S, Inukai M, Kogen H (2003b) Synthesis and antimicrobial activity of novel globomycin analogues. Bioorg Med Chem Lett 13:2315-2318

Kiho T, Nakayama M, Yasuda K, Miyakoshi S, Inukai M, Kogen H (2004) Structure-activity relationships of globomycin analogues as antibiotics. Bioorg Med Chem 12:337-361

Kim DY, Kim HW, Chung MG, Rhee YH (2007) Biosynthesis, modification, and biodegradation of bacterial medium-chainlength polyhydroxyalkanoates. J Microbiol 45:87-97

Kobayashi T, Hori Y (1993) Synthesis of biodegradable polyesters by polycondensation of methyl $(R)$-3-hydroxybutyrate and methyl $(R)-3$-hydroxyvalerate. Macromol Rapid Commun 14:785-790

Kobayashi S, Matsumura M, Furuta T, Hayashi T, Iwamoto S (1997) The asymmetric synthesis of sphingofungin $\mathrm{F}$ and the determination of its stereochemistry. Synlett 3:301-303

Kodicek E (1949) The effect of unsaturated fatty acids on grampositive bacteria. Symp Soc Exp Biol 3:217-232

Labeeuw O, Phansavath P, Genet JP (2004) Total synthesis of sulfobacin A through dynamic kinetic resolution of a racemic $[\beta]-k e t o-[\alpha]-$ amino ester hydrochloride. Tetrahedron: Asymmetry 15:1899-1908

Lee SY (2000) Bacterial polyhydroxyalkanoates. Biotechnol Bioeng 49:1-14

Lee SY, Lee Y (2003) Metabolic engineering of Escherichia coli for production of enantiomerically pure $(R)-(-)$-hydroxycarboxylic acids. Appl Environ Microbiol 69:3421-3426

Lee S, Lee K (2004) Method of preparing statins intermediates. Patent WO/2004/096789

Lee SY, Lee Y, Wang F (1999) Chiral compounds from bacterial polyesters: sugars to plastics to fine chemicals. Biotech Bioeng 65:363-368

Lee Y, Park SH, Lim IT, Han KB, Lee SY (2000) Preparation of alkyl $(R)-(-)-3$-hydroxybutyrate by acidic alcoholysis of poly-(R)-(-)-3hydroxybutyrate. Enzyme Microb Technol 27:33-36 
Lee SH, Park SJ, Lee SY, Hong SH (2008) Biosynthesis of enantiopure (S)-3-hydroxybutyric acid in metabolically engineered Escherichia coli. Appl Microbiol Biotechnol 79:633-641

Lemieux RU, Giguere J (1951) Biochemistry of the ustilaginales: the configurations of some beta-hydroxyacids and the bioreduction of beta-ketoacids. Can J Chem 29:678-681

Lengweiler UD, Fritz MG, Seebach D (1996) Monodisperse linear and cyclic oligo $[(R)-3$-hydroxybutanoates] containing up to 128 monomeric units. Helv Chim Acta 79:670-701

Lenz RW, Marchessault RH (2005) Bacterial polyesters: Biosynthesis, biodegradable plastics and biotechnology. Biomacromolecules 6:1-8

Li R, Chen Q, Wang PG, Qi QS (2007) A novel-designed Escherichia coli for the production of various polyhydroxyalkanoates from inexpensive substrate mixture. Appl Microbiol Biotechnol 75:1103-1109

Liu Q, Ouyang SP, Chung A, Wu Q, Chen GQ (2007) Microbial production of $R$-3-hydroxybutyric acid by recombinant $E$. coli harboring genes of $p h b A, p h b B$, and tesB. Appl Microbiol Biotechnol 76:811-818

Lopes MSG, Rocha RCS, Zanotto SP, Gomez JGC, da Silva LF (2009) Screening of bacteria to produce polyhydroxyalkanoates from xylose. World J Microbiol Biotechnol 25:1751-1756

Lynch JE, Volante RP, Wattley RV, Shinkai I (1987) Synthesis of an HMG-CoA reductase inhibitor-a diastereoselective aldol approach. Tetrahedron Lett 28:1385-1388

Marotta E, Pagani I, Righi P, Rosini G (1994a) Synthesis of methylsubstituted bicyclo[3.2.0]hept-3-en-6-ones and 3, 3a, 4, 6a-tetrahydro2H-cyclopenta[b]furan-2-ones. Tetrahedron 50:7645-7656

Marotta E, Piombi B, Righi P, Rosini G (1994b) N-bromosuccinimideinduced lactonization of bicyclo[3.2.0]hept-3-en-6-ones. J Org Chem 59:7526-7528

Marotta E, Righi P, Rosini G (1994c) A new, effective route to methyl substituted 3, 3a, 4, 6a-tetrahydro-2H-cyclopenta[b]furan-2-ones. Tetrahedron Lett 35:2949-2950

Martin CH, Prather KLJ (2009) High-titer production of monomeric hydroxyvalerates from levulinic acid in Pseudomonas putida. J Biotechnol 139:61-67

Martin OR, Zhou W, Wu XF, Front-Deschamps S, Moutel S, Schindl K, Jeandet P, Zbaeren C, Bauer JA (2006) Synthesis and immunobiological activity of an original series of acyclic lipid a mimics based on a pseudodipeptide backbone. J Med Chem 49:6000-6014

Massieu L, Hacesa ML, Montiela T, Hernández-Fonseca K (2003) Acetoacetate protects hippocampal neurons against glutamatemediated neuronal damage during glycolysis inhibition. Neuroscience 120:365-378

Morgan B, Burk M (2005) Methods for making simvatatin and intermediates. Patent WO/2005/040107

Mori K, Otaka K (1994) Synthesis of sphingofungin D and its stereoisomer at C14. Tetrahedron Lett 35:9207-9210

Munoz LEA, Riley MR (2008) Utilization of cellulosic waste from tequila bagasse and production of polyhydroxyalkanoate (PHA) bioplastics by Saccharophagus degradans. Biotechnol Bioeng 100:882-888

Nakahata M, Imaida M, Ozaki H, Harada T, Tai A (1982) The preparation of optically pure 3-hydroxyalkanoic acid-the enantiofacedifferentiating hydrogenation of the $\mathrm{C}=\mathrm{O}$ double-bond with modified Raney-nickel. Bull Chem Soc Jpn 55:2186-2189

Nieman C (1954) Influence of trance amounts of fatty acids on the growth of microorganisms. Bacteriol Rev 18:147-163

Nihei K, Hashimoto K, Miyairi K, Okuno T (2005) Enantioselective synthesis of four isomers of 3-hydroxy-4-methyltetradecanoic acid, the constituent of antifungal cyclodepsipeptides W493 A and B. Biosci Biotechnol Biochem 69:231-234

Noyori R, Ohkuma T, Kitamura M, Takaya H, Sayo N, Kumobayashi $\mathrm{H}$, Akutagawa S (1987) Asymmetric hydrogenation of $\beta$-keto carboxylic esters - a practical, purely chemical access to $\beta$ - hydroxy esters in high enantiomeric purity. J Am Chem Soc 109:5856-5858

Noyori R, Kitamura M, Ohkuma T (2004) Toward efficient asymmetric hydrogenation: architectural and functional engineering of chiral molecular catalysts. Proc Natl Acad Sci U S A 101:5356-5362

Numata K, Abe H, Doi Y (2008) Enzymatic processes for biodegradation of poly(hydroxyalkanoate)s crystals. Can J Chem-Rev Can Chim 86:471-483

Ohashi T, Hasegawa J (1992a) D-(-)- $\beta$-hydroxycarboxylic acids as raw materials for captopril and beta lactams. In: Collins AN, Sheldrake GN, Crosby J (eds) Chirality in Industry. John Wiley \& Sons Ltd, New York, pp 269-278

Ohashi T, Hasegawa J (1992b) New preparative methods for optically active $\beta$-hydroxycarboxylic acids. In: Collins AN, Sheldrake G, Crosby J (eds) Chirality in Industry. John Wiley \& Sons, New York, pp 249-268

Park SH, Lee SH, Lee SY (2001) Preparation of optically active $\beta$ amino acids from microbial polyester polyhydroxyalkanoates. J Chem Res-S 11:498-499

Park SJ, Lee SY, Lee Y (2004) Biosynthesis of (R)-3-hydroxyalkanoic acids by metabolically engineered Escherichia coli. Appl Biochem Biotechnol 114:373-379

Paterson I, Hulme AN (1995) Total synthesis of (-)-ebelactone A and (-)-ebelactone B1. J Org Chem 60:3288-3300

Pons JM, Kocienski P (1989) A synthesis of (-)-tetrahydrolipstatin. Tetrahedron Lett 30:1833-1836

Ren Q, Grubelnik A, Hoerler M, Ruth K, Hartmann R, Felber H, Zinn M (2005) Bacterial poly(hydroxyalkanoates) as a source of chiral hydroxyalkanoic acids. Biomacromolecules 6:2290-2298

Ren Zulian Q, Pletscher E, Zinn M, Thöny-Meyer L (2008) Method for the production of $R$-hydroxycarboxylic acids. Patent WO2008113190

Rich DH, Sun CQ, Guillaume D, Dunlap B, Evans DA, Weber AE (1989) Synthesis, biological activity, and conformational analysis of (2s, 3r, 4s)-mebmt1-cyclosporin, a novel 1-position epimer of cyclosporine A. J Med Chem 32:1982-1987

Rodriguez MJ, Belvo M, Morris R, Zeckner DJ, Current WL, Sachs RK, Zweifel MJ (2001) The synthesis of pseudomycin C via a novel acid promoted side-chain deacylation of pseudomycin A. Bioorg Med Chem Lett 11:161-164

Roth K (2005) Eine unendliche chemische Geschichte. Chem Unserer Zeit 39:212-217

Ruth K, Grubelnik A, Hartmann R, Egli T, Zinn M, Ren Q (2007) Efficient production of $(R)$-3-hydroxycarboxylic acids by biotechnological conversion of polyhydroxyalkanoates and their purification. Biomacromolecules 8:279-286

Sandoval A, Arias-Barrau E, Bermejo F, Canedo L, Naharro G, Olivera E, Luengo J (2005) Production of 3-hydroxy- $n$-phenylalkanoic acids by a genetically engineered strain of Pseudomonas putida. Appl Microbiol Biotechnol 67:97-105

Sarabia F, Chammaa S (2005) Synthetic studies on stevastelinstotal synthesis of stevastelins B and B3. J Org Chem 70:78467857

Satō T (1987) Synthesis of optically active forms of the $\delta$-lactone of 3 , 5-dihydroxydecanoic acid. Can J Chem 65:2732-2733

Sauer M, Porro D, Mattanovich D, Branduardi P (2008) Microbial production of organic acids: expanding the markets. Trends Biotechnol 26:100-108

Schmidt U, Siegel W (1987) Amino acids and peptides. Synthesis of (4R)-4-((E)-2-butenyl)-4, N-dimethyl-L-threonine (mebmt), the characteristic amino acid of cyclosporine. Tetrahedron Lett 28:2849-2852

Schreiber SL, Kelly SE, Porco JA, Sammakia T, Suh EM (1988) Structural and synthetic studies of the spore germination autoinhibitor gloeosporone. J Am Chem Soc 110:6210-6218 
Seebach D, Beck AK, Breitschuh R, Job K (1993) Direct degradation of the biopolymer poly $[(R)-3$-hydroxybutyric acid] to $(R)-3$ hydroxybutanoic acid and its methyl ester. Org Synth 71:39-47

Seebach D, Fritz MG (1999) Detection, synthesis, structure, and function of oligo(3-hydroxyalkanoates): contributions by synthetic organic chemists. Int J Biol Macromol 25:217-236

Seebach D, Albert M, Arvidsson P, Rueping M, Schreiber JV (2001) From the biopolymer PHB to biological investigations of unnatural $\beta$ - and $\gamma$-peptides. Chimia 55:345-353

Seuring B, Seebach D (1978) Syntheses and determination of the absolute-configurations of norpyrenophorin, pyrenophorin, and vermiculine. Liebigs Ann Chem 12:2044-2073

Sheldon RA (1996) Biocatalytic vs. chemical synthesis of enantiomerically pure compounds. Chimia 50:418-419

Shiraki M, Endo T, Saito T (2006) Fermentative production of $(R)-(-)$ -3-hydroxybutyrate using 3-hydroxybutyrate dehydrogenase null mutant of Ralstonia eutropha and recombinant Escherichia coli. J Biosci Bioeng 102:529-534

Sih CJ, Zhou BN, Gopalan AS, Shieh WR, Chen CS, Girdaukas G, Vanmiddlesworth F (1984) Enantioselective reductions of betaketo-esters by bakers-yeast. Ann Ny Acad Sci 434:186-193

Spengler J, Albericio F (2008) Asymmetric synthesis of $\alpha$ unsubstituted $\beta$-hydroxy acids. Curr Org Synth 5:151-161

Steinbüchel A, Valentin HE (1995) Diversity of bacterial polyhydroxyalkanoic acids. FEMS Microbiol Lett 128:219-228

Sudesh K, Abe H, Doi Y (2000) Synthesis, structure and properties of polyhydroxyalkanoates: biological polyesters. Prog Polym Sci 25:1503-1555

Sun Z, Ramsay J, Guay M, Ramsay B (2009) Fed-batch production of unsaturated medium-chain-length polyhydroxyalkanoates with controlled composition by Pseudomonas putida KT2440. Appl Microbiol Biotech 82:657-662

Sutter MA, Seebach D (1983) Synthesis of (2E, 4E, 6S, 7R, 10E, 12E, $14 \mathrm{~S}, 15 \mathrm{R})-6,7,14,15$-tetramethyl-8, 16-dioxa-2, 4, 10, 12-cyclohexadecatetraene-1, 9-dione- a model system for Elaiophylin. Liebigs Ann Chem 6:939-949

Tahara S, Mitzutani J (1978) Preparation of L-3-hydroxyalkanoic acids by fungal hydration of the corresponding trans-2-alkenoic acids. Agric Biol Chem 4:879-883

Tasaki O, Hiraide A, Shiozaki T, Yamamura H, Ninomiya N, Sugimoto H (1999) The dimer and trimer of 3-hydroxybutyrate oligomer as a precursor of ketone bodies for nutritional care. $\mathrm{J}$ Parenter Enteral Nutr 23:321-325

Tian PY, Shang LA, Ren H, Mi Y, Fan DD, Jiang M (2009) Biosynthesis of polyhydroxyalkanoates: current research and development. Afr J Biotechnol 8:709-714

Tieu K, Perier C, Caspersen C, Teismann P, Wu DC, Yan SD, Naini A, Vila M, Jackson-Lewis V, Ramasamy R, Przedborski S (2003) D$\beta$-Hydroxybutyrate rescues mitochondrial respiration and mitigates features of Parkinson disease. J Clin Invest 112:892-901

Touati R, Ratovelomanana-Vidal V, Ben Hassine B, Genet JP (2006) Synthesis of enantiopure $(R)-(-)$-massoialactone through rutheniumSYNPHOS $(R)$ asymmetric hydrogenation. Tetrahedron-Asymmetry 17:3400-3405

Tseng HC, Martin CH, Nielsen DR, Prather KLJ (2009) Metabolic engineering of Escherichia coli for enhanced production of $(R)$-and (S)-3-hydroxybutyrate. Appl Environ Microbiol 75:3137-3145

Utaka M, Watabu H, Higadhi W, Sakai T, Tsuboi S, Torii S (1990) Asymmetric reduction of aliphatic short- to long chain beta-keto acids by use of fermenting bakers' yeast. J Org Chem 55:3917-3921

Vanmiddlesworth F, Dufresne C, Wincott FE, Mosley RT, Wilson KE (1992) Determination of the relative and absolute stereochemistry of sphingofungin $\mathrm{A}$, sphingofungin $\mathrm{B}$, sphingofungin $\mathrm{C}$, and sphingofungin D. Tetrahedron Lett 33:297-300
Vollbrecht D, Schlegel HG (1978) Excretion of metabolites by hydrogen bacteria.2. Influences of aeration, ph, temperature, and age of cells. Eur J Appl Microbiol Biotechnol 6:157-166

Vollbrecht D, Schlegel HG (1979) Excretion of metabolites of hydrogen bacteria.3. D(-)-3-hydroxybutanoate. Eur J Appl Microbiol Biotechnol 7:259-266

Vollbrecht D, Elnawawy MA, Schlegel HG (1978) Excretion of metabolites by hydrogen bacteria.1. Autotrophic and heterotrophic fermentations. Eur J Appl Microbiol Biotechnol 6:145-155

Wang Z, Zhao C, Pierce ME, Fortunak JM (1999) Enantioselective synthesis of $\beta$-hydroxycarboxylic acids: direct conversion of $\beta$-oxocarboxylic acids to enantiomerically enriched $\beta$ hydroxycarboxylic acids via neighboring group control. Tetrahedron: Asymmetry 10:225-228

Wang L, Armbruster W, Jendrossek D (2007) Production of mediumchain-length hydroxyalkanoic acids from Pseudomonas putida in pH stat. Appl Microbiol Biotechnol 75:1047-1053

Wohlrab A, Lamer R, van Nieuwenhze MS (2007) Total synthesis of plusbacin A(3): a depsipeptide antibiotic active against vancomycin-resistant bacteria. J Am Chem Soc 129:4175-4177

Wu YK, Sun YP (2005) Novel chemoselective tosylation of the alcoholic hydroxyl group of syn- $\alpha, \beta$-disubstituted $\beta$-hydroxy carboxylic acids. Chem Commun 14:1906-1908

Wu Q, Zheng Z, Xi JZ, Gao HJ, Chen GQ (2003) Production of hydroxyalkanoate monomers by microbial fermentation. J Chem Eng Jpn 36:1170-1173

Xie CH. Yokota A (2005) Reclassification of Alcaligenes latus strains IAM 12599(T) and IAM 12664 and Pseudomonas saccharophila as Azohydromonas lata gen. nov., comb. nov., Azohydromonas australica sp nov and Pelomonas saccharophila gen. nov., comb. nov., respectively. Int J Syst Evol Microbiol 55:2419-2425

Yu J, Chen L (2008) The greenhouse gas emissions and fossil energy requirement of bioplastics from cradle to gate of a biomass refinery. Environ Sci Technol 42:6961-6966

Yu J, Stahl H (2008) Microbial utilization and biopolyester synthesis of bagasse hydrolysates. Bioresour Technol 99:8042-8048

Yuan MQ, Shi ZY, Wei XX, Wu QO, Chen SF, Chen GQ (2008) Microbial production of medium-chain-length 3-hydroxyalkanoic acids by recombinant Pseudomonas putida KT2442 harboring genes fadL, fadD and phaZ. FEMS Microbiol Lett 283:167-175

Zhang H, Liao ZX, Yue JM (2004) Five new sesquiterpenoids from Parasenecio petasitoides. HeIv Chim Acta 87:976-982

Zhang L, Shi ZY, Wu Q, Chen GQ (2009a) Microbial production of 4hydroxybutyrate, poly-4-hydroxybutyrate, and poly(3-hydroxybutyrate-co-4-hydroxybutyrate) by recombinant microorganisms. Appl Microbiol Biotechnol 84:909-916

Zhang XJ, Luo RC, Wang Z, Deng Y, Chen GQ (2009b) Application of (R)-3hydroxyalkanoate methyl esters derived from microbial polyhydroxyalkanoates as novel biofuels. Biomacromolecules 10:707-711

Zhao K, Tian G, Zheng Z, Chen JC, Chen GQ (2003) Production of D-(-)-3-hydroxyalkanoic acid by recombinant Escherichia coli. FEMS Microbiol Lett 218:59-64

Zhao Y, Zou B, Shi ZY, Wu Q, Chen GQ (2007) The effect of 3hydroxybutyrate on the in vitro differentiation of murine osteoblast MCM-E1 and in vivo bone formation in ovariectomized rats. Biomaterials 28:3063-3073

Zheng Z, Gong Q, Chen GQ (2004) Novel method for production of 3-hydroxydecanoic acid by recombinant Escherichia coli and Pseudomonas putida. Chin J Chem Eng 12:550-555

Zlicar M (2007) Process for the synthesis of rosuvastation calcium. Patent WO/2007/017117A1

Zou XH, Li HM, Wang S, Leski M, Yao YC, Yang XD, Huang QJ, Chen GQ (2009) The effect of 3-hydroxybutyrate methyl ester on learning and memory in mice. Biomaterials 30:1532-1541 